suggest that lower legal limits of blood alcohol concentration should have been stipulated in the 1967 Road Safety Act, but they do not allow us to predict the effects of now lowering the legal limits in a new road safety act. Let us not lose sight, in our quest for scientific credibility, of the primary objective of any new legislation-that is, to bring about an appreciable change in the population's behaviour and beliefs with regard to drink-driving.

Guppy cites the results of a study in the Australian Capital Territory, where legal blood alcohol concentrations were reduced from $17 \cdot 4$ $\mathrm{mmol} / \mathrm{l}$ to $10.9 \mathrm{mmol} / \mathrm{l}$. Although this seems to have resulted in a worthwhile reduction in "drinkdriving behaviour" in the first year, there is nothing to suggest that this will be sustained. If the experiences of 1967 are repeated then this is likely to be only a temporary change in behaviour. It is premature to use these results to justify a change in legislation on "scientific" grounds.

The weight of evidence suggests that the perceived risk of detection is the most important factor in bringing about a sustained change in drink-driving behaviour. ${ }^{2}$ It is on this that research and resources should be focused. One way would be to assess the effects of discretionary breath testing on the driving population. The substantial morbidity and mortality from road traffic accidents related to alcohol demand a reappraisal of the countermeasures presently in use. This is likely to be meaningful only if we maintain a clear sight of our long term objectives.

MARK DAVIES

Mawbey Brough Health Centre, London SW8 2UD

1 Guppy A. At what alcohol concentration should drink-driving be illegal? $B M \mathcal{F}$ 1994;308:1055-6. (23 April.)

2 Dunbar JA, Pentilla A, Pikkarainen J. Drinking and driving: choosing the legal limits. BMF 1987;295:1458-60.

\section{Colour blindness}

\section{Screening in schools has no value}

EDITOR,-Although screening for colour blindness is commonly carried out in schools, I do not believe it serves any useful purpose. Furthermore, as described by Trisha Greenhalgh, ${ }^{1}$ a positive result unnecessarily stigmatises a child, causes distress to parents, and leads to frequently erroneous occupational advice. When I was a senior house officer in an august London teaching hospital, I was the only junior ophthalmologist who was not red-green colour blind. Needless to say, we were all men.

Royal Victoria Infirmary,

Newcastle upon Type NE1 4LP

1 Greenhalgh T. Bad genes. BMf 1994;308:1167. (7 May.)

\section{Is a minor inconvenience}

EDITOR,-When Trish Greenhalgh describes redgreen colour blindness as "a poisoned dart" she is being less than fair to her son and other people who are red-green colour blind. Being red-green colour blind myself, I can assure her that I have never found it more than a minor inconvenience. Therefore, when I realised six years ago that I had passed this characteristic on to my eldest grandchild I had no reason to feel "bowled over" by the "personal ignominy of having passed bad genes down to posterity." Even if the characteristic was a cause of major handicap I believe that to speak of it in such emotive terms would be unhelpful and could encourage discrimination against those affected.

Most of the discrimination that I have experienced as a red-green colour blind person has come from electricians, epidemiologists, and editors.
Electricians stopped being at fault when they switched from using red and black to brown and blue for live and neutral wires, but some of my fellow epidemiologists and their editors still use greens and reds for areas of low and high incidences of disease in maps. As people with redgreen colour blindness account for several per cent of the population, epidemiologists should use colours that do not cause problems-for example, shades ranging from dark to light blue instead of greens, and from dark brown to yellow instead of reds.

IAN LECK

Woodstock, Professor emeritus

Oxford OX20 1UW

1 Greenhalgh T. Bad genes. BMF 1994;308:1 167. (30 April.)

\section{Rehabilitation needs after severe head injury}

EDIToR,-Though I agree that the cognitive, behavioural, and emotional disturbances that may occur after severe head injury are the predominant factors responsible for longer term handicap, I dispute R J Greenwood and colleagues' statement that physical deficits "usually recover rapidly and completely." "For several weeks or months after severe injury the physical sequelae account for a considerable proportion of the skilled physiotherapy, occupational therapy, and speech and language therapy provided to facilitate maximal potential recovery and prevent the physical and psychological complications that are likely to result from the lack of such input.

The facts that the median length of initial hospital stay was 25 days for the controls and 35 days for the case managed patients; that 44 of the 117 cases and controls who entered the study were inpatients in a rehabilitation unit for three or four months; and that most had many hours of physiotherapy as inpatients or outpatients, or both, hardly indicates a speedy physical recovery. Although the score on the Bond neurophysical scale at six months after injury is given and indicates persisting physical problems, the paper does not establish that physical deficits had completely recovered by 24 months. The other measures of residual disability and handicap are presented in a form that does not allow readers to determine whether physical problems persisted.

It would be regrettable if, because they highlight the lack of facilities to meet the longer term psychosocial needs of these patients, the authors were taken as suggesting that the provision of services to address the patients' physical rehabilitation requirements was either adequate or, worse, unnecessary. I am sure that this was not their intention.

Astley Ainslie Hospital

BRIAN PENTLAND

Edinburgh $\mathrm{EH} 9$

1 Greenwood RJ, McMillan TM, Brooks DN, Dunn G, Brock D, Dinsdale $S$, et al. Effects of case management after severe head injury. BMF 1994;308:1199-205. (7 May.)

\section{NHS complaints procedures}

\section{Consider financial compensation}

EDITOR,-The report of the review committee on NHS complaints procedures, with its emphasis on accessibility, impartiality, simplicity, speed of resolution, and cost effectiveness, has been generally well received. ${ }^{12}$ Unfortunately, however, it does not address the problem of serious adverse clinical events which may result in a claim for financial compensation. The committee states that its terms of reference excluded considerations of civil litigation. Yet I estimate that this year the hospital complaints procedure will cost the nation less than $£ 5$ million; medicolegal claims will cost well over $£ 100$ million. The minister of health proposes to tackle the problem of litigation by establishing a central fund to cover the cost of the largest claims to minimise the amount of money diverted from patients' care. It is far from clear, however, that this will prove to be effective in improving the quality of care and reducing the number of claims.

The present medicolegal system is slow, cumbersome, expensive, and often unfair. Most cases take more than two years to resolve; those going to court may take five years or more. With such delays the criteria for an adequate procedure as stated by the review committee ("the earlier [the action], the fuller the response may be and the sooner any action to improve the quality of service can be taken") cannot be met.

The minister for health should be persuaded to grasp this nettle. It is not sufficient to accept the statement "Where complainants suffer compensatable harm as a result of NHS treatment, the NHS should not try to avoid its responsibilities towards them or to withhold information." Are those seeking compensation to be encouraged to complain and then to use the resulting report to support their case through the courts? Or will the minister consider setting up a fairer system of compensation independent of the court action?

Four years ago Smith addressed the problem of adverse clinical events in hospital practice and indicated the need for a national survey. ${ }^{3}$ His suggestions were ignored. The chief medical officer, Kenneth Calman, has urged the profession to take the initiative in shaping health care. ${ }^{4} \mathrm{We}$ should move away from the adversarial means of resolving claims for compensation and seek to improve a system that may pay $£ 1$ million to the parents of a brain damaged infant if lawyers are satisfied that a clinician can be held to have been negligent yet nothing to the parents of an infant who has a God given defect of equal magnitude.

GRAHAM NEALE
Consultant physician

Addenbrooke's NHS Trust,

Cambridge CB2 2QQ

1 Department of Health. Being heard. The report of a review committee on NHS complaints and procedures. London: $\mathrm{DoH}$ 1994

2 Forsythe M. New NHS complaints procedure. BMf 1994;308: 1315-6. (21 May.)

3 Smith R. The epidemiology of malpractice. BMF 1990;301: 621-2.

4 Smith R. Challenging doctors: an interview with England's chief medical officer. BMF 1994;308:1221-4. (7 May.)

\section{Similar process exists in general practice}

EDIToR,- The proposed two stage NHS complaints procedure ${ }^{i}$ already, in effect, operates for complaints in general practice. Many practices have in house, informal procedures, and many family health services authorities have informal conciliatory procedures. These broadly equate with stage I of the proposed procedure. ${ }^{1-4}$ The proposed stage II or panel review equates with the current formal, service committee procedure. Thus not only have Professor Alan Wilson and his colleagues largely ignored the pleas made over the past two years by general practitioners that their system should be changed but they are now suggesting that this system should be extended to all other areas of the NHS. ${ }^{5}$ Those unfamiliar with the current general practice procedure will find that the proposed new system leaves a lot to be desired.

There are no grounds for the assumption that if these proposals are adopted there will be fewer formal complaints about the services provided by the NHS. Currently the complainant or patient 
decides whether a complaint should be dealt with by a formal procedure. As a result, general practitioners have faced time consuming and stressful investigations and hearings, even when the complaint concerned a trivial matter. Officers dealing with complaints in general practice have not been held accountable for deciding whether to go to a formal hearing in any particular case. Satisfying the complainant has been the object of complaints procedures in general practice, not necessarily ensuring that justice is being done.

General practitioners facing a complaint in the past have been found in breach of their terms of service in areas not covered by the complaint. The chief executive or, in primary care, a specially appointed complaints executive will therefore need not only to check that the issues are clearly stated and appropriate but to be held accountable for deciding whether a complaint should be rejected before stage II is initiated.

General practitioners are in a position to forewarn their NHS colleagues of the taste of things to come. Before accepting the proposals our leaders should seek clarification on the aforementioned points and, indeed, many others that general practitioners are anxious about.

Rosedale Surgery,

Cariton Colville,

Lowestoft, Suffolk NR33 8SH

1 Forsythe M. New NHS complaints procedure. $B M F$ 1994;308: 1315-6. (21 May.)

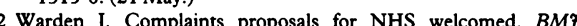
1994;308:1322. (21 May.)

3 O'Driscoll FA. Complaints review has failed. Monitor Weekly 1994;7(22):15.

4 Pietroni PC, de Uray-Rau S. Informal complaints procedure in general practice. $B M \mathcal{F} 1994 ; 308: 1546-8$. (11 June.)

5 Department of Health. Being heard. The report of a review committee on NHS complaints and procedures. London: $\mathrm{DoH}$ 1994.

\section{Pregnancy and immunity}

EDrTor,- The idea of a fetus acting as an allograft is fascinating.' The concept of localised complex signalling systems, with signals passing from the conceptus to the mother throughout pregnancy, is appealing and is given further credence by evidence that embryo derived suppressor factors may play a part in early implantation. ${ }^{2}$ Gordon $M$ Stirrat uses the absence of HLA antigens on the synctiotrophoblast to back up his statement that "immune adaptation is not required for the mother to cope with the fetus as an allograft."

The fetal-maternal allograft is often quoted as an immunological paradox. Several immunological features that arise during pregnancy are paradoxical to the editorial's main theme. For instance, there is clearly a modulation away from cell mediated immunity (a fact acknowledged in the editorial), which may entail suppression of interleukin-2. ${ }^{3}$ This immunomodulation results in the maternal serum becoming highly immunosuppressive during the second and, especially, the third trimesters of pregnancy.

Furthermore, research into recurrent spontaneous abortion also indirectly indicates that other maternal immune adaptations occur. Despite the absence of HLA antigens on the synctiotrophoblast, couples who share too many HLA antigens seem to be more prone to recurrent spontaneous abortion. ${ }^{4}$ Women suffering from recurrent spontaneous abortion seem to fail to make antibodies to their partner's lymphocyte antigens, ${ }^{4}$ although a clear mechanism explaining the need for antipaternal antibodies in maternal serum has not been established. ${ }^{4}$ Certain allergic conditions (my unpublished data) and certain immunological conditions, such as rheumatoid arthritis, ${ }^{5}$ improve considerably during pregnancy, which perhaps provides further evidence of a more generalised

immunosuppression arising from the modulation of cell mediated immunity.

Further research will almost certainly show that most mothers remain immunocompetent through out pregnancy, but the above mentioned paradoxes suggest that we are still viewing only the tip of the iceberg with regard to the complex immunology of pregnancy. More careful study of cancers arising de novo in pregnancy, the complications of certain cancers during pregnancy (breast cance and non-Hodgkin's lymphoma, for example), and other diseases (allergies, systemic lupus erythematosus, other autoimmune conditions) may throw more light on the matter. In particular, we need to recognise that, especially during the third trimester of pregnancy, some mothers may be appreciably immunosuppressed.

SAMMY LEE

Director

Andrology Clinic,

Hale Clinic,

London WIN 3HE

1 Stirrat GM. Pregnancy and immunity. BMf 1994;308:1385-6. (28 May.)

2 Daya S, Lee S, Underwood J. Mowbray JF, Craft IL, Clark DA Prediction of outcome following in vitro fertilized human embryos by measurement of embryo-derived suppressor factor. In: Clark DA, Croy BA, eds. Reproductive immunology. factor. In: Clark DA, Croy BA, eds.

3 Nicholas NS, Panayi GS, Nouri AME. Human pregnancy serum inhibits interleukin-2 production. Clin Exp Immunol 1984;58: $587-95$.

4 Underwood JL, Mowbray JF. The immunological approach to the treatment of human recurrent spontaneous abortion by immunization with lymphocytes. In: Chaouat G, ed. The immunology of the fetus. Florida: CRC Press, 1990:307-14.

5 Holland D, Bretscher P, Russell AS. Immunologic and inflammatory responses during pregnancy. F Clin Lab Immunol 1984;14:177-9.

\section{Safety and magnetic resonance imaging}

EDITOR,-Ivan Moseley gives a wide ranging review of the prostheses that may be adversely affected by magnetic resonance imaging.' ${ }^{1}$ To this should be added the prostheses that are used in otolaryngology. Hearing aids, particularly those "in the canal," are easily overlooked and may be damaged. Some grommets have a wire attachmen to aid their removal and are therefore theoretically at risk of displacement. Steel wire is also a component of some stapes prostheses, displacement of which may cause deafness, vertigo, and tinnitus. Other metallic objects that are occasionally used include clips to ligate branches of the maxillary artery and staples after excision of a pharyngeal pouch.

As patients may be unaware of the details of their surgical history, it may be prudent to consider issuing cards after surgery that provide information on the use of metallic objects or prostheses.

HAMID DAYA

Registrar NEIL WEIR

Department of Otolaryngology

Royal Surrey County Hospital,

Guildford GU2 5XX

1 Moseley I. Safety and magnetic resonance imaging. $B M$ 1994;308:1181. (7 May.)

\section{Pituitary tumours}

EDITOR,-Andrew Levy and Stafford L Lightman review the diagnosis and management of pituitary tumours. ${ }^{1}$ Our practice differs from theirs in one important aspect.

The authors suggest that if the circulating cortisol concentration increases to over $495 \mathrm{nmol} / \mathrm{l}$ in response to $250 \mu \mathrm{g}$ of tetracosactrin then glucocorticoid replacement is unnecessary. The use of the short tetracosactrin test as a substitute for the insulin tolerance test for postoperative assessment of the hypothalamic-pituitary-adrena axis remains controversial. Stewart et al have suggested that the short tetracosactrin test is generally sufficient and that the insulin tolerance test should be reserved for patients who yield an abnormal result in the short tetracosactrin test. ${ }^{2}$ We have reservations about this and reviewed the results of all paired short tetracosactrin and insulin tolerance tests performed in the past three years in our investigation unit. Among the 27 patients in whom the insulin tolerance test yielded an abnormal result the cortisol concentration was over $500 \mathrm{nmol} / 1$ at 30 minutes in four whereas it had reached this value at 60 minutes in 10 . If the criterion of a circulating cortisol concentration of $700 \mathrm{nmol} / \mathrm{l}$ at 30 minutes had been used no patients would have been missed, whereas if a cortisol concentration of $650 \mathrm{nmol} / 1$ had been used two patients would have been missed. The value at 30 minutes provides a better indication of the function of the hypothalamic-pituitary-adrenal axis. The short tetracosactrin test may be a safe, simple, cheap, and reasonably reliable substitute for the insulin tolerance test, but the cortisol concentration considered to represent a normal response remains undetermined. Registrar in endocrinology P KENDALL-TAYLOR Professor of endocrinology P H BAYLIS

Royal Victoria Infirmary, Newcastle upon Tyne NE1 4LP

1 Levy A, Lightman SL. Diagnosis and management of pituitary tumours. BMF 1994;308:1087-91. (23 April.)

2 Stewart PM, Corrie J, Seckl JR, Edwards CR, Padfield PL. A rational approach for assessing the hypothalamic-pituitaryadrenal axis. Lancet 1994;343:1208-10.

\section{Finns defined patients' rights before Dutch}

EdITOR,-A new, comprehensive law on patients' status and rights in Finland took effect on 1 March 1993 after a long period of preparation. Thus Finland was the first country in Europe, one year before the Netherlands, ${ }^{1}$ to pass a law defining the responsibilities of health professionals to their patients.

The Finnish Act on Status and Rights of Patients concerns the care and treatment of patients in all health care settings. The act thus covers municipal, private, and state health care. Every person who lives permanently in Finland is, without discrimination, entitled to the medical care required by his or her state of health within the limits of the resources that are available to health care at the time.

The aim of the new law is to secure patients' rights to health care of good quality and to self determination. The patient has a right to refuse a certain treatment or measure and to be cared for, as far as possible, in another medically acceptable way in mutual understanding. The act covers, among other things, access to treatment, patients' right to be informed, the right to self determination, the status of patients who are minors and the powers of a representative of the patient, emergency treatment, complaints and the patients' ombudsman, patients' documents, and confidentiality of information in patients' documents.

In addition to this act we have a law concerning injuries to patients, which took effect on 1 May 1987. It has created an insurance system, which compensates for personal injuries suffered in connection with health and medical care.

A bill concerning health care professionals and their practice, registration, and control is currently being considered by parliament. The aim has been to include all health care workers, be they medical, 